\title{
Home Phototherapy During the COVID-19 Pandemic
}

\author{
Akshitha Thatiparthi, BS; Amylee Martin, BS; Jeffrey Liu, BS; Jashin J. Wu, MD
}

\section{PRACTICE POINTS}

- Home phototherapy is a safe and effective option for patients with psoriasis during the coronavirus disease 2019 (COVID-19) pandemic.

- Although a consensus has not been reached with systemic immunosuppressive therapies for patients with psoriasis and the risk of COVID-19, we continue to recommend caution and careful monitoring of clinical outcomes for patients.

$\square$ ffice-based phototherapy practices have closed or are operating below capacity because of the coronavirus disease 2019 (COVID-19) pandemic. $^{1}$ Social distancing measures to reduce virus transmission are a significant driving factor. ${ }^{1-3}$ In the age of biologics, other options requiring fewer patient visits are available, such as UVB phototherapy. UV phototherapy is considered first line when more than $10 \%$ of the body surface area is affected. ${ }^{4}$ Although phototherapy often is performed in the office, it also may be delivered at home. ${ }^{2}$ Home-based phototherapy is safe, effective, and similar in cost to office-based phototherapy. ${ }^{4}$ Currently, there are limited COVID-19-specific guidelines for homebased phototherapy.

The risks and sequelae of COVID-19 are still being investigated, with cases varying by location. As such, local and national public health recommendations are evolving. Dermatologists must make individualized decisions about practice services, as local restrictions differ. As officebased phototherapy services may struggle to implement mitigation strategies, home-based phototherapy is an increasingly viable treatment option. ${ }^{1,4,5}$ Patient benefits of home therapy include improved treatment compliance; greater patient satisfaction; reduced travel/waiting time; and reduced long-term cost, including co-pays, depending on insurance coverage. ${ }^{2,}$

We aim to provide recommendations on home-based phototherapy during the pandemic. Throughout the decision-making process, careful consideration of safety, risks, benefits, and treatment options for physicians, staff, and patients will be vital to the successful implementation of home-based phototherapy. Our recommendations are based on maximizing benefits and minimizing risks.

\section{Considerations for Physicians}

Physicians should take the following steps when assessing if home phototherapy is an option for each patient. ${ }^{1,2,4}$

- Determine patient eligibility for phototherapy treatment if currently not on phototherapy

- Carefully review patient and provider requirements for home phototherapy supplier

- Review patient history of treatment compliance

- Determine insurance coverage and consider exclusion criteria

- Review prior treatments

- Provide education on side effects

- Provide education on signs of adequate treatment response

- Indicate the type of UV light and unit on the prescription

- Consider whether the patient is in the maintenance or initiation phase when providing recommendations

- Work with the supplier if the light therapy unit is denied by submitting an appeal or prescribing a different unit

Ms. Thatiparthi is from the College of Osteopathic Medicine of the Pacific, Western University of Health Sciences, Pomona, California. Ms. Martin is from the School of Medicine, University of California, Riverside. Mr. Liu is from the Keck School of Medicine, University of Southern California, Los Angeles. Dr. Wu is from the Dermatology Research and Education Foundation, Irvine, California.

Ms. Thatiparthi, Ms. Martin, and Mr. Liu report no conflict of interest. Dr. Wu is or has been an investigator, consultant, or speaker for AbbVie, Almirall, Amgen, Arcutis, Aristea Therapeutics, Boehringer Ingelheim, Bristol-Myers Squibb, Dermavant, Dr. Reddy's Laboratories, Eli Lilly, Galderma, Janssen, LEO Pharma, Mindera, Novartis, Regeneron, Sanofi Genzyme, Solius, Sun Pharmaceutical, UCB, Valeant Pharmaceuticals North America LLC, and Zerigo Health.

Correspondence: Jashin J. Wu, MD (jashinwu@gmail.com).

doi:10.12788/cutis.0172 
- Follow up with telemedicine to assess treatment effectiveness and monitor for adverse effects

\section{Considerations for Patients}

Counsel patients to weigh the risks and benefits of home phototherapy prescription and usage..$^{1,2,4}$

- Evaluate cost

- Carefully review patient and provider requirements for home phototherapy supplier

- Ensure a complete understanding of treatment schedule

- Properly utilize protective equipment (eg, genital shields for men, eye shields for all)

- Avoid sharing phototherapy units with household members

- Disinfect and maintain units

- Maintain proper ventilation of spaces

- Maintain treatment log

- Attend follow-up

\section{Treatment Alternatives}

For patients with severe psoriasis, there are alternative treatments to office and home phototherapy. Biologics, immunosuppressive therapies, and other treatment options may be considered on a case-by-case basis., ${ }^{3,46}$ Currently, recommendations for the risk of COVID-19 with biologics or systemic immunosuppressive therapies remains inconsistent and should be carefully considered when providing alternative treatments. ${ }^{7-11}$

\section{Final Thoughts}

As restrictions are lifted according to local public health measures, prepandemic office phototherapy practices may resume operations. Home phototherapy is a practical and effective alternative for treatment of psoriasis when access to the office setting is limited.

\section{REFERENCES}

1. Lim HW, Feldman SR, Van Voorhees AS, et al. Recommendations for phototherapy during the COVID-19 pandemic. J Am Acad Dermatol. 2020;83:287-288

2. Anderson KL, Feldman SR. A guide to prescribing home phototherapy for patients with psoriasis: the appropriate patient, the type of unit, the treatment regimen, and the potential obstacles. J Am Acad Dermatol. 2015;72:868.E1-878.E1.

3. Palmore TN, Smith BA. Coronavirus disease 2019 (COVID-19): infection control in health care and home settings. UpToDate. Updated January 7, 2021. Accessed January 25, 2021. https://www.uptodate.com/contents/coronavirus-disease-2019 -covid-19-infection-control-in-health-care-and-home-settings

4. Koek MB, Buskens E, van Weelden H, et al. Home versus outpatient ultraviolet $\mathrm{B}$ phototherapy for mild to severe psoriasis: pragmatic multicentre randomised controlled non-inferiority trial (PLUTO study). BMJ. 2009;338:b1542.

5. Sadeghinia A, Daneshpazhooh M. Immunosuppressive drugs for patients with psoriasis during the COVID-19 pandemic era. a review [published online November 3, 2020]. Dermatol Ther. 2020:E14498. doi:10.1111/dth.14498

6. Damiani G, Pacifico A, Bragazzi NL, et al. Biologics increase the risk of SARS-CoV-2 infection and hospitalization, but not ICU admission and death: real-life data from a large cohort during red-zone declaration. Dermatol Ther. 2020;33:E13475.

7. Lebwohl M, Rivera-Oyola R, Murrell DF. Should biologics for psoriasis be interrupted in the era of COVID-19? J Am Acad Dermatol. 2020;82:1217-1218

8. Mehta P, Ciurtin C, Scully M, et al. JAK inhibitors in COVID-19: the need for vigilance regarding increased inherent thrombotic risk. Eur Respir J. 2020;56:2001919.

9. Walz L, Cohen AJ, Rebaza AP, et al. JAK-inhibitor and type I interferon ability to produce favorable clinical outcomes in COVID-19 patients: a systematic review and meta-analysis. BMC Infect Dis. 2021;21:47.

10. Carugno A, Gambini DM, Raponi F, et al. COVID-19 and biologics for psoriasis: a high-epidemic area experience-Bergamo, Lombardy, Italy. J Am Acad Dermatol. 2020;83:292-294.

11. Gisondi P, Piaserico S, Naldi L, et al. Incidence rates of hospitalization and death from COVID-19 in patients with psoriasis receiving biological treatment: a Northern Italy experience [published online November 5, 2020].J Allergy Clin Immunol. doi:10.1016/j.jaci.2020.10.032 